\title{
The importance of non-linear relationships between attitude and behaviour in policy research
}

\author{
Jenny van Doorn · Peter C. Verhoef • \\ Tammo H. A. Bijmolt
}

Received: 10 April 2006/Accepted: 8 January 2007/Published online: 5 April 2007

(C) Springer Science+Business Media B.V. 2007

\begin{abstract}
The relation between consumers' attitude and behaviour is of importance in designing marketing and public policy measures. However, many empirical studies find only low effects of attitudes on behaviour. In this paper, we suggest that the conflicting evidence on the attitude-behaviour link is partly due to only extreme attitudes impacting behaviour. That is, possible non-linearities not detected by standard linear models could occur in the relationship between attitudes and behaviour. We present and compare alternative model specifications to assess the non-linear relationship. We test our view using empirical examples relating to the link between environmental concerns and the purchase of organic products, and the link between privacy concerns and the possession of loyalty cards. We find strong support for the appearance of a non-linear relationship between environmental concern and the purchase of organic products, while only weak support for such a relationship between privacy concern and the possession of loyalty cards.
\end{abstract}

Keywords Attitude extremity - Spline regression - Organic products ·

Loyalty programs · Privacy concerns

One particularly intriguing observation in the field of marketing research is that some attitudes have a strong impact on consumer behaviour, whereas some other attitudes do not influence a person's actions at all. An example from the field of environmental policy is that many consumers, to some extent, care about the environment. Despite this, they often do not behave in an environmentally friendly fashion, which is for example reflected in small market shares for organic products. One answer presented in literature is that this is due to a difference in attitude strength (Holland, Verplanken \& Van Knippenberg, 2002;

J. van Doorn $(\bowtie) \cdot$ P. C. Verhoef · T. H. A. Bijmolt

Faculty of Economics, Department of Marketing, University of Groningen, PO Box 800, 9700 AV

Groningen, The Netherlands

e-mail: j.van.doorn@rug.nl 
Peterson \& Dutton, 1975): Only "extreme" attitudes will drive behaviour, meaning that the relationship between attitudes and attitude-related behaviour is non-linear. For public policy, this observation is critical, as it implies that a change in attitude does not necessarily have to result in a behavioural change. Thus, policy measures aiming at changes in consumer behaviour by influencing consumer attitudes might not be successful.

Recently, non-linear effects of attitudes on behaviour have gained renewed attention in the marketing literature. Remarkably, these non-linear effects have mainly been investigated in the satisfaction-loyalty literature (e.g., Agustin \& Singh, 2005). This is probably due to the strong conceptual attention for this non-linear link (Oliver, Rust \& Varki, 1997). In the area of public policy, non-linear relationships are often not considered empirically (e.g., Bredahl, 2001; Phelps, Nowak \& Ferrell, 2000). For instance, in the effect of environmental concern on environmentally friendly behaviour researchers predominantly assume linear relationships (e.g., Schultz, 2001). Still, also here one might argue that only consumers with extreme attitudes, that is, with very high environmental concerns, will behave in an environmentally friendly fashion.

The objective of this paper is to emphasize both theoretically and empirically the relevance of the non-linear relationship between attitudes and behaviour, with a special focus on the importance of extreme attitudes. We present quadratic, exponential, and spline regression as possibilities to account for non-linear relationships. The remainder of this paper is organized as follows. In the subsequent section, we provide a short overview of the literature on the attitude-behaviour link. We discuss rationales underlying the relationship between attitudes and behaviour. The models we use to estimate the non-linear relationship between attitudes and behaviour are presented subsequently. Next, we examine non-linearities in the attitude-behaviour link using two specific empirical applications addressing public policy-related issues: (1) the relationship between environmental concerns and the purchase of organic products, and (2) the relationship between privacy concerns and the possession of loyalty cards. We end with a discussion of the implications of our study.

\section{The role of attitude extremity in the attitude-behaviour link}

Attitudes can be defined "as a learned predisposition to respond in a consistently favourable or unfavourable manner with respect to a given object' (Fishbein \& Ajzen, 1975 , p. 15). The popularity of the attitude construct in the social sciences-which can be deduced from the large amount of theoretical and empirical literature on this topic-is due to the fact that attitudes are supposed to have an impact on, and even predict, behaviour (Kraus, 1995). Still, empirical research on the attitude-behaviour link has been yielding contradictory results. In an early literature review, Wicker (1969, p. 65) concluded that "it is considerably more likely that attitudes will be unrelated or only slightly related to overt behaviours than that attitudes will be closely related to action.' Ajzen and Fishbein (1980), however, attributed the weak relationship between attitudes and behaviour found in earlier literature to the incompatibility between the attitudes measured and the related behaviour. The results of the later reviews by Schuman and Johnson (1976), Kim and Hunter (1993), and Kraus (1995) diverged from Wicker's (1969) results, as they found that attitudes are rather consistent with future behaviour. Yet, Kraus (1995) pointed out that attitudes account on average for only $14 \%$ of the variance in behaviour, and that in 17 of the 88 studies in his meta-analysis no significant attitude-behaviour relationship could be established. 
In the light of conflicting evidence on the strength of the attitude-behaviour link, possible non-linearities in the link between attitudes and behaviour gain attention. Methodological shortcomings with respect to the measurement scales are one possible explanation for non-linearities presented in literature (Ajzen \& Fishbein, 1977; Kim \& Hunter, 1993). Another approach to explain a varying intensity of the attitude-behaviour-link is the strength of an attitude. Attitude strength consists of various dimensions, such as attitude importance (the subjective significance of an attribute), attitude accessibility, and attitude extremity (Bizer \& Krosnick 2001; Krosnick, Boninger, Chuang, Berent \& Carnot, 1993). For our investigation, we selected one of these dimensions, namely, attitude extremity, because (1) attitude extremity plays a key role in most conceptions of attitude strength, and (2) it has proven to be a successful predictor of behaviour (Peterson \& Dutton, 1975; Raden, 1985). Attitude extremity can be described as the degree of favourableness or unfavourableness towards an object or person (Peterson \& Dutton, 1975). According to literature, extreme attitudes should have strong behavioural consequences, whereas both weak and moderate attitudes often do not have much impact on behaviour (Abelson, 1995; Judd \& Brauer, 1995). Furthermore, we focus on the main effect of attitude extremity on behaviour, although previous literature also used attitude strength as a moderator (Kraus, 1995). The reason for focusing on the main effect is that in public policy research, mostly the direct relation between the valence of an attitude and related behaviour is investigated, such as the relation between environmental attitudes and environmentally friendly behaviour.

An explanation for the importance of extreme attitudes is given in behavioural decision theory. People are supposed to display the behaviour from which they expect the largest subjective utility (Edwards, 1954). Whereas attitude itself is not necessarily formed by the utility paradigm, attitude-related behaviour can very well be explained by drawing on the expected utility of behavioural choices (Agarwal \& Malhotra, 2005; Zajonc, 1980). In the case of weak or moderate attitudes, not much utility is attached to complying or noncomplying with these attitudes, that is, they do not play a major role in the cost-benefit analysis of behavioural alternatives. In this constellation, behaviour is largely guided by costs and benefits not related to the attitude. This can also be labelled as the "zone of indifference" (Oliver, Rust \& Varki, 1997). However, if an attitude becomes more extreme, at some point it will exceed a certain threshold. Then, perceived costs will be exceeded considerably by perceived benefits and behaviour will be guided by attitudes (Jaccard, Radecki, Wilson \& Dittus, 1995). Outside the zone of indifference a stronger relationship (either positive or negative) between attitude and behaviour is thus expected. These attitude-behaviour relations are graphically displayed in Fig. 1.

\section{Modelling the non-linear attitude-behaviour relationship}

Figure 1 suggests that specific functional forms, in particular non-linear model specifications, should be used to describe the relationship between attitudes and behaviour. In literature, quadratic and exponential specifications are most commonly used to capture the non-linear impact of attitudes on behaviour (Bowman \& Narayandas, 2004).

The quadratic regression model consists of adding a quadratic term of the independent variables to the linear regression model, thus allowing for non-linear functional forms (Leeflang, Wittink, Wedel \& Naert, 2000, p. 67):

$$
Y=\alpha_{0}+\beta_{0} \cdot X+\beta_{1} \cdot X^{2}
$$


Fig. 1 Proposed non-linear relationship between attitudes and behaviour

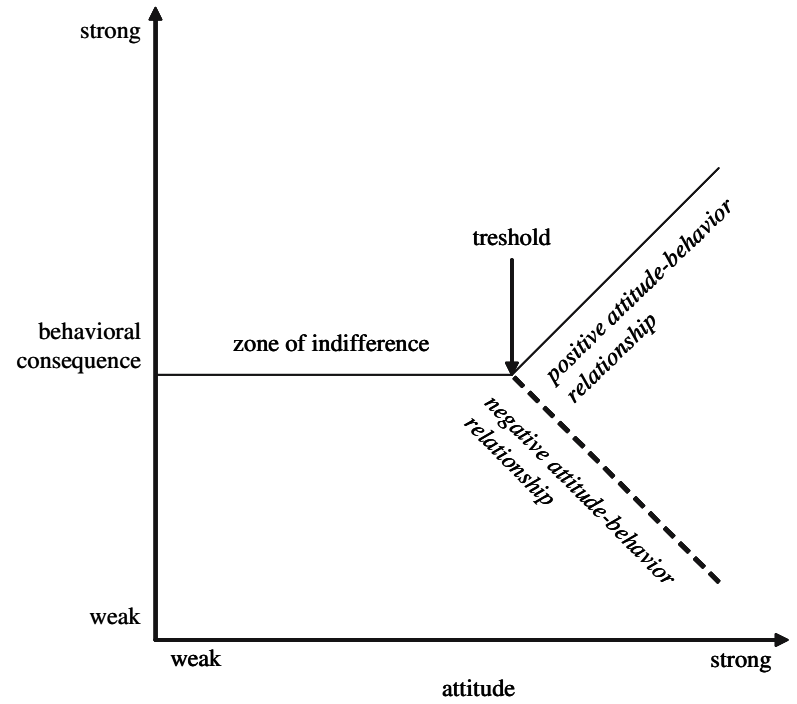

Depending on the parameter values $\beta_{0}$ and $\beta_{1}$, attitude will have a more or less strong positive or negative impact on behaviour. Also, the impact may change in sign within the range of observed values. However, the impact does change gradually instead of showing a break at a certain threshold.

An alternative model to represent the stronger behavioural impact of extreme attitudes is an exponential specification (Bowman \& Narayandas, 2004):

$$
Y=\alpha_{0}+\beta_{0} \cdot X+\beta_{1} \cdot \exp (X)
$$

Due to the exponential transformation of the explanatory variable, the effect on behaviour will increase with an increase in $X$. Similar to the quadratic model; the exponential model assumes a more gradual change of impact.

Another useful model specification is spline regression, which has less frequently been applied. As this technique is less well known than quadratic and exponential model specifications, we will discuss the spline model in more detail. With spline regression, one can explicitly model a slope change in a regression equation at a certain threshold (Greene, 2003; Marsh \& Cormier, 2001). The regression equation consists of a number of line segments, varying with respect to the slope parameter. The threshold values where the line segments meet are referred to as spline knots. In spline regression, the first step is to create spline adjustment variables $Z_{j}$ that represent the different spline knots. These have to be specified for every point of the model where one anticipates a slope change. We define the sequence of spline knots as $j=1, \ldots, J$, corresponding threshold values as $X_{j}$, and the spline adjustment variables $Z_{j}$ as

$$
Z_{j}=D_{j}\left(X-X_{j}\right) \quad \text { with } D_{j}=0 \text { for } X \leq X_{j} \text { and } D_{j}=1 \text { for } X>X_{\mathrm{j}} \text {. }
$$

The spline regression model consists of the "basic" linear relationship between Y and $\mathrm{X}$, along with the spline adjustment variables $Z_{j}$ :

$$
Y=\alpha_{0}+\beta_{0} \cdot X+\sum_{j=1}^{J} \beta_{j} \cdot Z_{j}
$$


In literature, different spline regression techniques are discussed; they differ with respect to the specification of the number and location of the spline knots (see for an overview Marsh \& Cormier, 2001). As we do not wish to specify the number of knots and their locations beforehand, we use the estimation method developed by Marsh (1986). This method specifies a large number of spline knots and lets stepwise regression analysis determine the knots that are statistically significant. Hence, it does not require a beforehand specification of the point of slope change, which is an advantage compared to the methods used in the literature on the satisfaction-loyalty link.

Comparing the alternative model specifications, spline regression allows a close approximation of the functional form between attitudes and behaviour as presented in Fig. 1. It explicitly models the threshold at which the effect of attitude on behaviour changes. Compared to spline regression, the exponential and quadratic regression model resembles this functional form less accurately, as these models imply a gradually changing impact of attitudes on behaviour instead of a break at a certain threshold. Next, we present two empirical studies in which we compare the performance of the alternative non-linear model specifications.

\section{Empirical applications}

To illustrate potential non-linearities in the relation between attitudes and behaviour, we use two empirical applications in public policy, namely, the purchase of organic products depending on consumers' expressed environmental concerns and the possession of loyalty cards depending on consumers' privacy concerns. Both attitudes have already been related to behaviour, but we suggest that their behavioural impact can be better explained when accounting for attitude extremity.

\section{Application 1: Purchase of organic products}

\section{Description of application 1}

In our first empirical application, we investigated consumers' purchase of organic products. We expected only high degrees of environmental concern to be strongly positively related to the purchase of organic products. For respondents with less extreme attitudes, the benefits of organic products would presumably not outweigh the costs, such as higher prices or higher transaction costs for travelling to a specialized store (Grunert \& Juhl, 1995). That is, apart from attitudes, contextual factors are influential on pro-environmental behaviour (Stern, 1999). This should result in a zero or weak attitude-behaviour relationship in the range of low to moderate attitudes. The relationship thus resembles the upwards-shaped curve in Fig. 1.

We collected data by means of a questionnaire, in which respondents were inquired about their purchase of several categories of organic products, like meat, bread, and vegetables. We measured environmental concern by applying scales developed in literature (see appendix and Dunlap \& Van Liere, 1978; Noe \& Snow, 1990), and embedded these in a longer questionnaire. This way, respondents could not discern the goal of our research and were not inclined to pretend to having a higher attitude-behaviour 
consistency than they actually did. We mailed the questionnaire to randomly selected 2,000 Dutch households and obtained a response of 309 consumers (response rate of $15.5 \%$ ). After elimination of the cases that were unusable due to missing values, 266 responses remained.

The five items for environmental concern had a good internal consistency with a Cronbach's Alpha of 0.71 , thus exceeding the critical threshold of 0.7 (Nunnally \& Bernstein, 1994). We use the average of the items measuring environmental concern; where zero denotes a low environmental concern and six denotes a high environmental concern. The distribution of the responses is presented in Table 1. We assume that the data are of equal interval and apply ordinary regression analysis. An alternative would be to use ordinal regression analysis. However, this would require a large number of additional parameters. Furthermore, the dependent variable in our analysis is the average of multiple items instead of the value of a single rating scale. Finally, there is some empirical evidence that the assumption of equal intervals with data measure on a rating scale is often reasonable (Gregoire \& Driver, 1987).

For the spline model, we define the spline adjustment variables $Z_{j}$ at $j=1.5,2,2.5,3$, 3.5, 4, 4.5, 5 and 5.5. We use the MKSPLINE procedure provided by STATA to accomplish this. To estimate our model, we use the stepwise regression procedure in STATA. To account for consumer heterogeneity, we include socio-demographic variables (gender, age, income, household situation, education, house ownership) as dummy variables.

As dependent variable, we use a variable denoting the self-reported number of organic product categories bought by a consumer on a regular basis. We include all the sociodemographics in the model and apply the stepwise selection technique to the attitudinal spline adjustment variables $Z_{j}$.

Estimation results of application 1

Table 2 provides the estimation results of the linear regression model and the three alternative non-linear models.

Table 1 Distribution of the responses

\begin{tabular}{|c|c|c|c|c|c|c|c|}
\hline \multicolumn{2}{|c|}{$\begin{array}{l}\text { Environmental } \\
\text { concern }\end{array}$} & \multicolumn{2}{|c|}{$\begin{array}{l}\text { No. of organic } \\
\text { products } \\
\text { purchased }\end{array}$} & \multicolumn{2}{|c|}{ Privacy concerns } & \multicolumn{2}{|c|}{$\begin{array}{l}\text { No. of } \\
\text { loyalty cards }\end{array}$} \\
\hline$\leq 2$ & $3.0 \%$ & 0 & $33.8 \%$ & 1 & $5.1 \%$ & 0 & $2.2 \%$ \\
\hline$>2-3$ & $18.4 \%$ & 1 & $30.5 \%$ & 1.5 & $4.6 \%$ & 1 & $7.6 \%$ \\
\hline$>3-4$ & $22.9 \%$ & 2 & $16.5 \%$ & 2 & $16.5 \%$ & 2 & $18.2 \%$ \\
\hline$>4-5$ & $32 \%$ & 3 & $5.3 \%$ & 2.5 & $15.6 \%$ & 3 & $19.5 \%$ \\
\hline \multirow[t]{5}{*}{$>5-6$} & $23.7 \%$ & 4 & $4.9 \%$ & 3 & $26.6 \%$ & 4 & $15.7 \%$ \\
\hline & & 5 & $3.4 \%$ & 3.5 & $12.8 \%$ & 5 & $10.9 \%$ \\
\hline & & $\geq 6$ & $5.6 \%$ & 4 & $10.6 \%$ & 6 & $22.2 \%$ \\
\hline & & & & 4.5 & $5.1 \%$ & $\geq 7$ & $3.7 \%$ \\
\hline & & & & 5 & $3.1 \%$ & & \\
\hline
\end{tabular}


Table 2 Model results for the effect of environmental concerns on the purchase of organic products

\begin{tabular}{lcccc}
\hline Variables & Linear model & Quadratic model & Exponential model & Spline model \\
\hline Constant & -1.064 & 1.346 & 0.350 & -0.084 \\
Environmental concern & $0.345^{* *}$ & -0.931 & -0.114 & 0.083 \\
$Z_{5}$ & n.a. & n.a. & n.a. & $1.485^{* *}$ \\
Environmental concern ${ }^{2}$ & n.a. & $0.160^{*}$ & n.a. & n.a. \\
exp(Environmental concern) & n.a. & n.a. & $0.005^{* *}$ & n.a. \\
Female & $0.791^{* * *}$ & $0.789^{* *}$ & $0.795^{* *}$ & $0.791^{* *}$ \\
Age 25-34 & 0.048 & 0.044 & 0.044 & 0.040 \\
Age 35-44 & 0.318 & 0.365 & 0.386 & 0.411 \\
Age 45-54 & 0.687 & 0.630 & 0.640 & 0.671 \\
Age 55-64 & $0.992^{*}$ & $0.956^{*}$ & $0.953^{*}$ & $0.967^{*}$ \\
Age 65 and above & 0.261 & 0.237 & 0.242 & 0.261 \\
Average income & 0.080 & 0.045 & 0.062 & 0.057 \\
Average to double average income & 0.348 & 0.279 & 0.282 & 0.300 \\
Above double average income & 0.194 & 0.105 & 0.049 & 0.018 \\
Couple, no children & 0.136 & 0.114 & 0.094 & 0.092 \\
Single with children & 0.603 & 0.611 & 0.651 & 0.667 \\
Couple with children & 0.355 & 0.332 & 0.339 & 0.341 \\
Vocational training & -0.642 & -0.642 & -0.687 & -0.717 \\
Secondary education & -0.371 & -0.385 & -0.417 & -0.425 \\
College education & -0.107 & -0.079 & -0.082 & -0.080 \\
Renting a house/apartment & 0.523 & 0.449 & 0.415 & 0.410 \\
$R^{2}$ & 0.161 & 0.178 & 0.185 & 0.190 \\
AIC & 1062.41 & 1059.19 & 1056.92 & 1055.23 \\
BIC & 1126.78 & 1127.14 & 1124.86 & 1123.18 \\
\hline
\end{tabular}

* $P<0.05$

** $P<0.01$

It can be seen in Table 2 that the effects of the socio-demographic variables are limited, but stable across all model specifications. In all models, female consumers and consumers between 55 and 64 years of age are more likely to purchase organic products.

In the linear model specification, environmental concern has a significant positive effect on the number of product categories in which a consumer purchases organic products. However, by allowing a non-linear model specification, the link between environmental concern and the purchase of organic products can be much better explained, which can seen from the considerable increase in $R^{2}$ for the non-linear models. According to the $R^{2}$, the spline regression model performs best. However, the $R^{2}$ does not account for the additional variables added to the model due to the non-linear specifications. Also, classical testing procedures for model selection cannot be used because the models are non-nested (e.g., Greene, 2003). Therefore, we take into account the Akaike Information Criterion (AIC) and the Bayesian Information Criterion (BIC), both of which penalize model expansion (Greene, 2003). When comparing non-nested models, the use of these criteria is most practical to balance model fit and model parsimony. With both AIC and BIC being lowest for the spline model, these criteria favour the spline model as well. 
Fig. 2 Effects of environmental concerns on the purchase of organic products according to the four model specifications

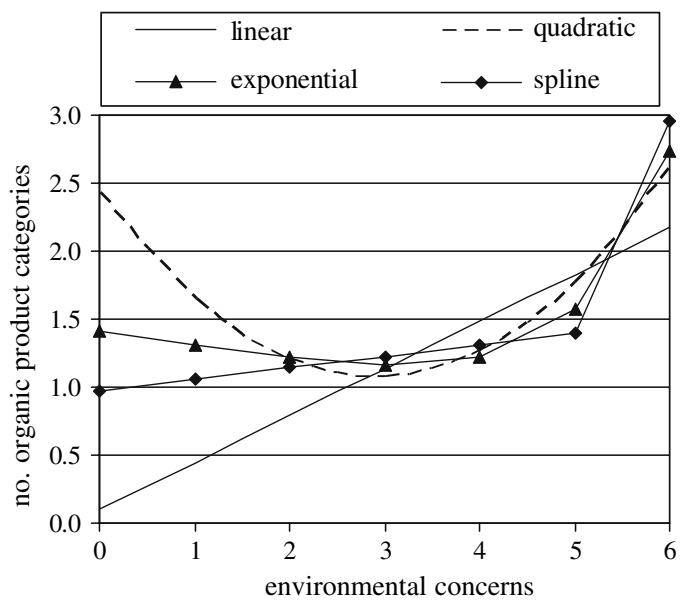

In the spline model, the stepwise procedure selects a change in effect parameter at the threshold value 5, while all other spline knots are not significant. Concerning the other two non-linear models, the exponential model is also better suited than the linear model to capture the stronger behavioural consequences of extreme attitudes. The quadratic model outperforms the linear model on only two out of three fit-statistics, which makes it less preferable than the spline and exponential specification. ${ }^{1}$ The parameter pertaining to the non-linear term of the environmental concern effect is significant in both the quadratic and exponential model.

To further understand the non-linear effect of environmental concern on the purchase of organic products, we graphically show the relationship according to the four estimated models in Fig. 2. To obtain this figure, we varied environmental concern from zero to six and inserted average values for all other explanatory variables. The interpretation of the linear model is straightforward: the average respondent with minimum environmental concerns purchases organic products in 0.10 categories, and the expected number of product categories increases by 0.345 with any 1 point-increase in environmental concern. In the spline model, consumers with very low environmental concerns are predicted to purchase organic products in 0.98 categories, which is substantial higher than in the linear model. The effect of the "basis" environmental concern-variable is relatively small (0.083) and not significant. However, with a threshold value of five on the scale, environmental concern has a very strong impact $(0.083+1.485)$. Hence, the relation between environmental concern and the purchase of organic products is negligible for environmental concern below five, but for extremely high levels of environmental concern the relation is much stronger than in the linear model. The curve of the exponential model shows the strongest resemblance to the spline model: Actually, there is not much of an effect before environmental concern exceeding a value of about five. The functional form of the quadratic model deviates from the other models and least resembles the relationship between attitude and behaviour we presume in Fig. 1.

\footnotetext{
1 We also estimated a model with a cubic term, which performed worse than the spline model on all three fit statistics.
} 
Hence, we conclude that a linear model does not adequately capture the relationship between environmental concern and the purchase behaviour with respect to organic products. The true relations are in fact masked in the linear model, as the weak (or nonexisting) relationship in the low to moderate regions of the attitudinal scale and the strong correlation in the endpoints of the scale are not captured. The spline model is best suited to describe the true attitude-behaviour relationship, although the exponential model also performs quite well.

\section{Application 2: Possession of loyalty cards}

\section{Description of application 2}

In our second empirical application, we examine the number of loyalty cards consumers possess depending on their privacy concerns. Loyalty programmes generate a number of important benefits to consumers, such as presents and other rewards, (customized) promotions, sponsored magazines, and the thrill of collecting points (Dowling \& Uncles, 1997). However, loyalty programmes may also have a negative side for consumers (O’Malley \& Prothero, 2004). In particular, loyalty cards imply purchase data being tracked and observed by others (Dowling \& Uncles, 1997). The attitude considered here (privacy concerns) is expected to be negatively related to the possession of loyalty cards. As loyalty cards are generally associated with benefits for customers, however, we expect only consumers with severe privacy concerns to display a significant attitude-behaviour relationship (Milne \& Gordon, 1993). Thus, the relationship between privacy concerns and the possession of loyalty cards is expected to resemble the downwards shaped curve in Fig. 1.

A large-scale survey has been conducted in the Netherlands, as part of the so-called Relationship Builder project in collaboration with the Carlson Marketing Group. The project studies customer relationship management in general and loyalty programmes in particular. Six companies from six different industries, namely financial services, food industry, oil industry, telecom, utilities, and retailing, participated in the project. Each company provided a sample of 10,000 customers. In the spring of 2004 , these customers were contacted by e-mail with the request to fill in an internet-based questionnaire. The questionnaire consisted of a general part on customer relationship management and loyalty programmes and a confidential company-specific part.

To indicate their possession of loyalty cards, respondents had to denote their membership of 24 widespread loyalty programmes in the Netherlands. Respondents could also specify the possession of other loyalty cards in addition to the ones included in our list. In a second task, respondents were asked to indicate how many loyalty cards they owned in total. We then used the maximum of the number of cards indicated in the first task and the number of owned cards reported in the second task as our behavioural measure. The questionnaire contained two items measuring privacy concerns we developed for this study, since existing scales on privacy concerns do not address the context of loyalty programmes. The scale ranged from one (weak privacy concerns) to five (severe privacy concerns) (see appendix). The items on privacy concerns showed sufficient internal consistency with a correlation of 0.53 . Hence, we averaged the items to obtain our measurement of privacy concerns. The frequency distribution of the scale is presented in Table 1. 
We eliminated cases with missing data and obtained a sample of 3657 respondents. We estimated regression models comparable to our first empirical application with a consumer's level of privacy concerns as attitudinal variable and socio-demographics accounting for customer heterogeneity. Again we use ordinary regression analysis to estimate a linear model and three alternative non-linear models. For the spline models, we specified spline adjustment variables $Z_{j}$ at $j=1.5,2,2.5,3,3.5,4$, and 4.5.

\section{Estimation results of Application 2}

The results can be taken from Table 3. The effects of the socio-demographic variables are highly consistent across the four models. Income plays an important role; the number of

Table 3 Model results for the effect of privacy concerns on the possession of customer cards

\begin{tabular}{|c|c|c|c|c|}
\hline Variables & Linear model & Quadratic model & Exponential model & Spline model \\
\hline Constant & $2.644^{* *}$ & $2.114^{* *}$ & $2.394^{* *}$ & $2.212^{* *}$ \\
\hline Privacy & $-0.136^{* *}$ & 0.260 & -0.008 & 0.077 \\
\hline $\mathrm{Z}_{2.5}$ & n.a. & n.a. & n.a. & $-0.314^{\text {*** }}$ \\
\hline Privacy $^{2}$ & n.a. & $-0.067^{*}$ & n.a. & n.a. \\
\hline $\exp ($ Privacy $)$ & n.a. & n.a. & $-0.005^{*}$ & n.a. \\
\hline Female & $0.898^{* *}$ & $0.889^{* *}$ & $0.890^{* * *}$ & $0.888^{* *}$ \\
\hline Age $25-34$ & 0.076 & 0.079 & 0.077 & 0.080 \\
\hline Age $35-44$ & $0.309^{*}$ & $0.308^{*}$ & $0.308^{*}$ & $0.307^{*}$ \\
\hline Age $45-54$ & $0.273^{*}$ & $0.267^{*}$ & $0.265^{*}$ & $0.268^{*}$ \\
\hline Age 55-64 & $0.589^{* * *}$ & $0.581^{* *}$ & $0.581^{* * *}$ & $0.579^{* * *}$ \\
\hline Age 65 and above & 0.255 & 0.257 & 0.254 & 0.260 \\
\hline Income $20.000-40.000 €$ & $0.466^{* *}$ & $0.473^{* *}$ & $0.472^{* *}$ & $0.472^{* *}$ \\
\hline Income $40.001-60.000 €$ & $0.620^{* * *}$ & $0.627^{* * *}$ & $0.623^{* * *}$ & $0.628^{* *}$ \\
\hline Income $60.001-80.000 €$ & $0.855^{* *}$ & $0.861^{* * *}$ & $0.859^{* * *}$ & $0.862^{* *}$ \\
\hline Income $80.001-100.000 €$ & $1.102^{* *}$ & $1.116^{* *}$ & $1.113^{* * *}$ & $1.115^{* *}$ \\
\hline Income over $100.000 €$ & $1.146^{* *}$ & $1.151^{* *}$ & $1.147^{* * *}$ & $1.152^{* *}$ \\
\hline Single, no children & 0.079 & 0.080 & 0.081 & 0.078 \\
\hline Couple, no children & $0.352^{*}$ & $0.345^{*}$ & $0.348^{*}$ & $0.343^{*}$ \\
\hline Single with children & 0.295 & 0.290 & 0.287 & 0.291 \\
\hline Couple with children & $0.451^{* *}$ & $0.443^{* *}$ & $0.447^{* *}$ & $0.440^{* * *}$ \\
\hline High school education & 0.112 & 0.115 & 0.115 & 0.116 \\
\hline Secondary education & 0.013 & 0.021 & 0.023 & 0.017 \\
\hline Vocational degree & 0.187 & 0.191 & 0.192 & 0.187 \\
\hline College education & 0.218 & 0.231 & 0.232 & 0.227 \\
\hline University degree & 0.186 & 0.204 & 0.205 & 0.202 \\
\hline Renting a house/apartment & $-0.228^{* *}$ & $-0.223^{* *}$ & $-0.224^{* *}$ & $-0.222^{* *}$ \\
\hline$R^{2}$ & 0.134 & 0.135 & 0.135 & 0.136 \\
\hline AIC & 14477.98 & 14473.03 & 14473.84 & 14471.93 \\
\hline $\mathrm{BIC}$ & 14620.68 & 14621.94 & 14622.74 & 14620.83 \\
\hline
\end{tabular}

* $P<0.05$

** $P<0.01$ 
Fig. 3 Effects of privacy concerns on the possession of loyalty cards according to the four model specifications

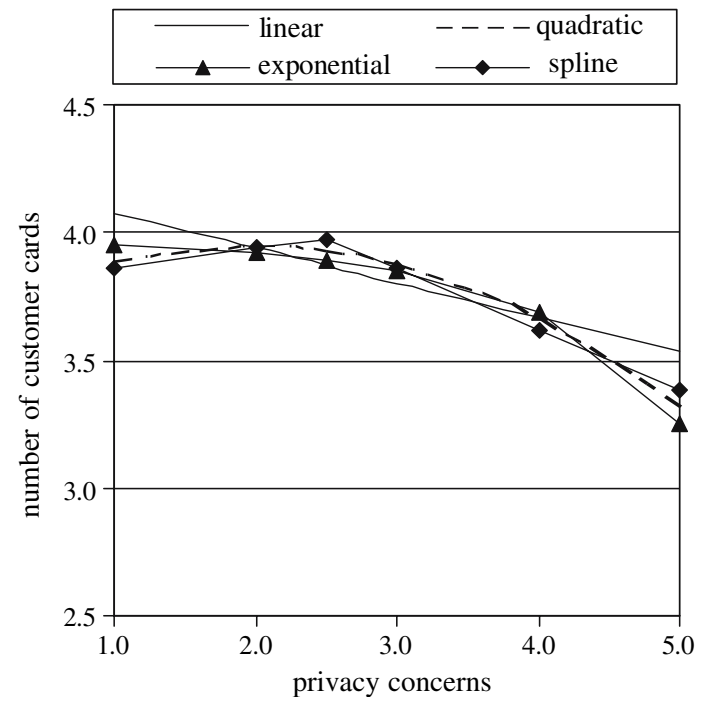

customer cards rises with increasing income. Also, women on average possess a larger number of customer cards than men. Consumers aged between 35 and 64 tend to have more loyalty cards than individuals aged below 35 or above 64; and consumers who live together with a partner have significantly more loyalty cards than single persons. Finally, consumers renting a house or apartment own a smaller number of customer cards than consumers owning a house or apartment.

It can be seen in Table 3 that the explanatory power of the model increases when allowing for a non-linear relation between privacy concerns and membership of loyalty programmes, albeit to a lesser extent than in our first empirical study. The $R^{2}$ is highest for the spline regression model. According to the AIC-statistic, the spline model also performs best, but the BIC-statistic is slightly lower for the linear model. This is due to the fact that the spline model uses one parameter more than the linear model, which is stronger penalized in the BIC-statistic than in the AIC-statistic. According to two out of three fit statistics, the spline regression model is preferable to the other models. The exponential and quadratic models outperform the linear model according to two out of three fit statistics as well, but provide a worse fit than the spline model for each of the statistics. ${ }^{2}$ Yet, we have to conclude from Table 3 that the non-linearities are weaker for this empirical application and that a linear model approximates the attitude-behaviour link quite well.

Figure 3 displays the functional forms of all four models. Compared to Fig. 2, the functional forms deviate less from each other, which reinforces the observation that the non-linearities in this example are weaker than in our first empirical study. Still, the parameter estimates of the linear and non-linear models reveal some differences. In the linear model, the possession of loyalty cards is predicted to decrease with 0.136 if privacy concerns increase with one point on the scale. In the spline model, only one spline knot is identified as being significant, namely, at a privacy concern score of 2.5 . The basis variable "privacy concerns" shows a very small positive effect, which is not significantly different from zero. This means that up to scores of 2.5 , privacy concerns have hardly any impact on

${ }^{2}$ Again, a cubic model is outperformed by the spline model. 
the number of possessed customer cards. For privacy scores of 2.5 and higher, the average number of customer cards decreases more rapidly than in the linear model, the slope of the regression line with 0.237 being steeper. The exponential and quadratic models show a similar curve compared to the spline model and also suggest that privacy concerns matter only for scores exceeding three.

With respect to the numerical interpretation for the linear model, the average individual having low privacy concerns holds 4.08 customer cards, with a reduction of 0.136 cards per scale point of privacy concerns. In the spline model, the average number of customer cards for a respondent with low privacy concerns is slightly lower (3.86). At the lower parts of the scale, the number of loyalty cards slightly increases (0.077) with a one point increase in privacy concerns, but the decrease rate for privacy concerns exceeding 2.5 is much higher than in the linear model $(0.077-0.314=-0.237)$. In the exponential (quadratic) model, the average individual with low privacy concerns possesses 3.95 (3.88) customer cards, with the rate of decrease with every point increase in privacy concerns being 0.005 multiplied with the exponential of privacy concerns ( 0.067 multiplied with the square of privacy concerns).

\section{Discussion}

In public policy and marketing research, attitudes have always been a major point of interest due to their presumed behavioural consequences. However, empirical evidence on the behavioural impact of attitudes is mixed, with some researchers claiming that attitudes have no or little behavioural consequence, others pointing out that attitudes are decisive for consumer behaviour (Kim \& Hunter, 1993; Kraus, 1995; Wicker, 1969). In this research, we suggest and demonstrate that conflicting evidence on the impact of attitudes on behaviour can be due to non-linear relations. We detected significant non-linearities in the relationship between attitude and behaviour in our first application, with spline regression models performing best. In our second application, we identified only mild non-linearities.

We can only speculate on the reason for this divergence. First, one reason might be that the attitude-behaviour relationship is stronger in our first empirical application than in our second one. While environmental concern should be a major predictor for the purchase of organic products, privacy concerns are more distant from the observed behaviour "enrolment in a loyalty programme.' The reason for this is that privacy concerns are one reason amongst several for or against the enrolment in a loyalty programme. On the one hand, this could increase the likelihood of observing non-linearities, since the other drivers of loyalty programme enrollment would override the privacy concerns if these are low. On the other hand, however, with generally weaker relations, an increase of the relationship at the extremes might be also less likely, which is probably what we observe here.

Second, our theory underlying the appearance of non-linear relationships between attitudes and behaviour argues that costs and benefits of this behaviour play an important role. Purchasing organic products might have clear benefits for consumers. Organic products are not only considered as environmentally friendly, but are also perceived as being tastier and having a higher quality. In contrast, not owning loyalty cards may provide consumers with fewer benefits. As a consequence, the effect of extreme attitudes is not as strong in this case, which leads to a smaller increase in explained variance.

The weaker support for non-linearities in the second application mimics findings in other areas of consumer research. For example, Streukens and De Ruyter (2004) do not find 
empirical support for non-linear relationships between satisfaction and customer loyalty. Our study suggests that non-linear relationships may appear in one context, while in another context these non-linearities are not so prevalent. Hence, we believe that for public policy research it is important to be aware of the potential appearance of these nonlinearities. Testing for these non-linearities with the discussed models will show whether non-linear relationships are present. We do, however, still have limited knowledge on which factors cause the presence of non-linear relationships. Future research should strive to gain a better understanding of these factors.

Our empirical applications thus demonstrate that the attitude-behaviour relation is not always straightforward and linear, but may display non-linearities. Extreme attitudes can have a strong impact on behaviour, whereas weak to moderate attitude evaluations might not have much of an effect. In the case of bipolar attitude measures, this might even imply a double-bent curve of the attitude-behaviour relationship, with both extreme positive and extreme negative attitudes having a stronger effect than more moderate ones. Spline regression would then be an adequate way of capturing this, because this method has the advantage that it allows multiple slope changes.

Hence, the empirical size of attitudinal effects on behaviour will depend on the initial attitude value. Ignoring these non-linearities bears consequences for the interpretation of the relation between attitudes and behaviour. In particular, one should not expect an attitude change to be followed by an equal change in behaviour, but one has to consider the initial attitude value before the change occurred. For instance, in our first empirical example, the linear model predicts that a one point increase in environmental concern for any respondent is followed by a 0.345 increase in product categories in which organic products are purchased. However, according to our spline model, this interpretation is not quite correct. If an attitude change occurs from two to three, this will have hardly any behavioural consequence: a predicted increase of 0.083 categories. If the attitude change occurs from five to six, however, an increase of the purchase of organic products with nearly one and a half product categories is predicted.

\section{Public policy implications}

This research has some implication for public policy makers. First, bearing in mind possible non-linearities in the attitude-behaviour link can be quite useful when designing marketing or public policy measures that aim at altering behaviour by changing consumers' attitudes. As behavioural responses initiated by attitude changes can be different than a linear model specification would suggest, segmenting consumers according to their attitude extremity before designing policy measures can be worthwhile. In many cases, it makes sense to target only those consumers close to or at the extreme points of the attitudinal scale. In the field of marketing, this is in fact already practiced by some companies by focusing on the so-called "Bottom 2-Box" and "Top 2-Box," respectively, for instance in the field of customer satisfaction. This implies that customers with a very low satisfaction with certain product or service features are identified and efforts are made to improve their satisfaction. The rationale behind this is that very low satisfaction evaluations have a greater propensity to drive behaviour, which in this case is churning behaviour (Anderson \& Mittal, 2000). Likewise, following the notion of customer delight, only very high satisfaction evaluations in the "Top 2-Box" are likely to drive customer retention, which means that efforts should be made to shift customers just beneath the "Top 2-Box" above the threshold. 
Second, in the field of public policy, it can also be advisable to focus on consumers with more extreme attitudes, in particular because attitudes such as, say, environmental concern should be harder to alter than satisfaction evaluations. Applied to our first empirical application, if one aims at stimulating the sales of organic products, it is most promising to target those consumers with already quite high environmental concerns. If one succeeds in changing their attitude, consumers still below the extremity threshold will cross it and consequently purchase more organic products. Consumers already above the extremity threshold will intensify their attitude-related behaviour in compliance with their attitude change. Consumers, whose environmental concern changes from "low" to "moderate" will, according to our results, hardly change their behaviour. Targeting these consumers is of not much use. Hence, segmenting consumers according to their attitude extremity prior to designing public policy measures might be worthwhile in terms of campaign efficiency.

Third, we demonstrate that for some attitudes, only extreme evaluations exert an influence on consumer behaviour, thus assuming linear and straightforward relations might not be adequate. Policy measures designed to change consumers' behaviour through a change of attitudes, can thus have quite different behavioural consequences for consumers with moderate and those with more extreme attitudes.

\section{Appendix}

Description of scales

Environmental concerns (Dunlap \& Van Liere, 1978; Noe \& Snow, 1990):

- Humans have the right to modify the natural environment to suit their needs. (r)

- Humans need not adapt to the natural environment because they can remake it to suit their needs. (r)

- Humans are placed above nature. (r)

- Plants and animals primarily exist to be used by humans. (r)

- Humans must live in harmony with nature in order to survive.

Privacy concerns:

- Loyalty cards form a threat to my privacy due to their registration system.

- I do not like companies to obtain information on my purchase behaviour by means of a loyalty programme.

\section{References}

Abelson, R. P. (1995). Attitude extremity. In R. E. Petty \& J. A. Krosnick (Eds.), Attitude strength: antecedents and consequences (pp. 25-41). Mahwah: Lawrence Erlbaum Associates.

Agarwal, J., \& Malhotra, N. K. (2005). An integrated model of attitude and affect: Theoretical foundation and an empirical investigation. Journal of Business Research, 58, 483-493.

Agustin, C., \& Singh, J. (2005). Curvilinear effects of consumer loyalty determinants in relational exchanges. Journal of Marketing Research, 42, 96-108.

Ajzen, I., \& Fishbein, M. (1977). Attitude-behavior relations: A theoretical analysis and review of empirical research. Psychological Bulletin, 84, 888-918.

Ajzen, I., \& Fishbein, M. (1980). Understanding attitudes and predicting social behavior. Englewood Cliffs, NJ: Prentice-Hall.

Anderson, E. W., \& Mittal, V. (2000). Strengthening the satisfaction-profit chain. Journal of Service Research, 3, 107-120. 
Bizer, G. Y., \& Krosnick, J. A. (2001). Exploring the structure of strength-related attitude features: The relation between attitude importance and attitude accessibility. Journal of Personality and Social Psychology, 81, 566-586.

Bowman, D., \& Narayandas, D. (2004). Linking customer management effort to customer profitability in business markets. Journal of Marketing Research, 41, 433-447.

Bredahl, L. (2001). Determinants of consumer attitudes and purchase intentions with regard to genetically modified food: Results of a cross-national survey. Journal of Consumer Policy, 24, 23-61.

Dowling, G. R., \& Uncles, M. (1997). Do customer loyalty programs really work? Sloan Management Review, 38, 71-82.

Dunlap, R. E., \& Van Liere, K. D. (1978). The “"new environmental paradigm:” A proposed measuring instrument and preliminary results. Journal of Environmental Education, 9, 10-19.

Edwards, W. (1954). The theory of decision making. Psychological Bulletin, 51, 380-417.

Fishbein, M., \& Ajzen, I. (1975). Belief, attitude, intention, and behavior: An introduction to theory and research. Reading, MA: Addison-Wesley.

Greene, W. H. (2003). Econometric analysis. Upper Saddle River: Prentice Hall.

Gregoire, T. G., \& Driver, B. L. (1987). Analysis of ordinal data to detect population differences. Psychological Bulletin, 101, 159-165.

Grunert, S. C., \& Juhl, H. J. (1995). Values, environmental attitudes and buying of organic foods. Journal of Economic Psychology. 16, 39-62.

Holland, R. W., Verplanken, B., \& van Knippenberg, A. (2002). On the nature of attitude-behavior relations: The strong guide, the weak follow. European Journal of Social Psychology, 32, 869-876.

Jaccard, J., Radecki, C., Wilson, T., \& Dittus, P. (1995). Methods for identifying consequential beliefs: Implications for understanding attitude strength. In R. E. Petty \& J. A. Krosnick (Eds.), Attitude strength: Antecedents and consequences (pp. 337-359). Mahwah: Lawrence Erlbaum Associates.

Judd, C. M., \& Brauer, M. (1995). Repetition and evaluative extremity. In R. E. Petty \& J. A. Krosnick (Eds.), Attitude strength: Antecedents and consequences (pp. 43-71). Mahwah: Lawrence Erlbaum Associates.

Kim, M. S., \& Hunter, J. E. (1993). Attitude-behavior relations: A meta-analysis of attitudinal relevance and topic. Journal of Communication, 43, 101-142.

Kraus, S. J. (1995). Attitudes and the prediction of behavior: A meta-analysis of the empirical literature. Personality and Social Psychology Bulletin, 21, 58-75.

Krosnick, J. A., Boninger, D. S., Chuang, Y. C., Berent, M. K., \& Carnot, C. G. (1993). Attitude strength: One construct or many related constructs? Journal of Personality and Social Psychology, 65, 11321151.

Leeflang, P. S. H., Wittink, D. R., Wedel, M., \& Naert, P. A. (2000). Building models for marketing decisions. Boston: Kluwer Academic Publishers.

Marsh, L. C. (1986). Estimating the number and locations of knots in spline regressions. Journal of Applied Business Research, 3, 60-70.

Marsh, L. C., \& Cormier, D. R. (2001). Spline regression models. Sage University Papers Series on Quantitative Applications in the Social Sciences, 07-137. Thousand Oaks, CA: Sage.

Milne, G. R., \& Gordon, M. E. (1993). Direct mail privacy-efficiency trade-offs within an implied social contract framework. Journal of Public Policy and Marketing, 12, 206-215.

Noe, F. P., \& Snow, R. (1990). The new environmental paradigm and further scale analysis. Journal of Environmental Education, 21, 20-26.

Nunnally, J. C., \& Bernstein, I. (1994). Psychometric theory. New York: McGraw-Hill.

Oliver, R. L., Rust, R. T., \& Varki, S. (1997). Customer delight: Foundations, findings, and managerial insight. Journal of Retailing, 73, 311-336.

O'Malley, L., \& Prothero, A. (2004). Beyond the frills of relationship marketing. Journal of Business Research, 57, 1286-1294.

Peterson, K. K., \& Dutton, J. E. (1975). Centrality, extremity, intensity: Neglected variables in research on attitude-behavior consistency. Social Forces, 54, 393-414.

Phelps, J., Nowak, G., \& Ferrell, E. (2000). Privacy concerns and consumer willingness to provide personal information. Journal of Public Policy and Marketing, 19, 27-41.

Raden, D. (1985). Strength-related attitude dimensions. Social Psychology Quarterly, 48(4), 312-330.

Schultz, P. W. (2001). The structure of environmental concern: Concern for self, other people, and the biosphere. Journal of Environmental Psychology, 21, 327-339.

Schuman, H., \& Johnson, M. P. (1976). Attitudes and behavior. Annual Review in Sociology, 2, 161-207.

Stern, P. C. (1999). Information, incentives, and proenvironmental consumer behavior. Journal of Consumer Policy, 22, 461-478. 
Streukens, S., \& Ruyter, K. de (2004). Reconsidering nonlinearity and asymmetry in customer satisfaction and loyalty models: An empirical study in three retail service settings. Marketing Letters, 15, 99-111.

Wicker, A. W. (1969). Attitudes versus actions: The relationship of verbal and overt behavioral responses to attitude objects. Journal of Social Issues, 25, 41-78.

Zajonc, R. B. (1980). Feeling and thinking: Preferences need no inferences. American Psychologist, 35, $151-175$. 